\title{
Screen-based media and young children: Review and recommendations
}

\author{
Catherine Thamarai a/p Arumugam, Mas Ayu Binti Said, Nik Daliana Binti Nik Farid \\ Arumugam CT, Said MA, Nik Farid ND. Screen-based media and young children: Review and recommendations. Malays Fam Physician. \\ 2021;16(2);7-13. https://doi.org/10.51866/rv1143
}

Keywords:

screen-based media, early

childhood

\section{Authors:}

\section{Catherine Thamarai \\ a/p Arumugam \\ (Corresponding author) \\ Medical Degree (MD), Master of \\ Public Health (MPH), Doctor in Public \\ Health (DrPH) Candidate \\ Department of Social and Preventive \\ Medicine, Faculty of Medicine, \\ University of Malaya, Kuala Lumpur \\ Malaysia}

Email: catherinethamarai@yahoo.com

\section{Mas Ayu Binti Said \\ MBBS, MPH (Epidemiology), PhD \\ Centre for Epidemiology and \\ Evidence-Based Practice (CEEBP) \\ Department of Social and Preventive \\ Medicine, Faculty of Medicine \\ University of Malaya, Kuala Lumpur \\ Malaysia}

Nik Daliana Binti Nik Farid MBBS (Adelaide), MPH (Malaya) DrPH (Malaya), Medical Lecturer and Public Health Specialist, Centre for Population Health (CePH)

Department of Social and Preventive Medicine, Faculty of Medicine University of Malaya, Kuala Lumpur Malaysia

\begin{abstract}
Early childhood development is influenced by a child's environmental experiences. The qualities of surrounding in which a child lives, grows up and learns are key for attaining their milestones. Increased availability of screen-based media in families leads to excessive screen time among young children, resulting in high chances of displacing parent-child interaction which is fundamental in a thriving child's process of learning and development.

Numerous publications have investigated the potential health impacts of early exposure and excessive usage of screen-based media among children, with literature suggesting links between excessive screen time and behavioural difficulties, developmental delay and increased risk of obesity, among other issues. Existing guidelines from international bodies call for limiting screen time to an hour per day for children aged two to five years old and urge that children below the age of two should not be exposed to any screen time.

To spark awareness among parents and caregivers concerning the potential health impacts of screen-based media usage among young children, child media habits are recommended to be incorporated as part of toddlers' developmental assessment in health clinics. A guideline for mindful usage of screen-based media focusing on children below the age of five tailored to a Malaysian context ought to be developed based on current evidence from research, theory and practice. A collaborative effort between concerned agencies is essential to ensuring a developmentally stimulating environment in which young children may grow up.
\end{abstract}

\section{Introduction}

Child development is defined as the continuous, sequential changes in the aspects of psychological, biological and emotional competencies that take place in human beings from birth until one reaches the adolescence period. ${ }^{1}$ The environmental experiences of a child are made up of various attributes that influence early childhood development, from stimulation and support of family to the wider scale of sociocultural, socio-economical and socio-political factors. The nurturing qualities of an intimate family depend on parenting skills, home environment, nutrition and safety. The qualities of surrounding in which a child lives, grows up and learns are key for attaining their milestones. ${ }^{2,3}$ Inadequate or inappropriate social and emotional experiences in a child's early life can compromise higher-level brain functioning that provides the processing information necessary to socially bond and respond. ${ }^{4}$ It is during this critical period that a child develops competencies of cognitive language, sensory motor and social emotional development. ${ }^{5}$
During these early years of a child's life, the presence of an enabling environment is of utmost importance. ${ }^{6}$ The deprivation of nurturing care and caregiver-child attachment in children below the age of three is a major concern. ${ }^{7}$ A poor mother-child relationship is associated with insecure infant attachment, resulting in long-lasting effects to the child. ${ }^{8}$ In contrast, increased interaction between caregiver and child through activities like reading together results in greater ability of vocalising words and higher sustainability of attention among toddlers. ${ }^{9}$ How a child absorbs learning, interprets observation and responds to the environment largely depends on what he or she receives from parents or caregivers at home - in other words, the immediate environment he or she thrives in. ${ }^{5}$

In the past few decades, the environment in which a child grows has been saturated by the advancement of technology. As the term 'screen time' covers multiple types of screen-based media in the current era, the way children receive, process and respond to content of newer media may be different 
than it was before, with traditional media. Traditional media, such as television and radio result in passive viewing or listening whereby the user is not involved in alteration of the media content. Newer digital media, however, comprise social and interactive media that allow users to actively make use of and create media content. Examples of newer media include smartphones and tablets. ${ }^{10}$ Increased availability of mobile devices in families has boosted the accessibility and ownership of screen-based media among young children, with a United Kingdom survey stating that nearly a quarter $(21 \%)$ of toddlers three to four years of age possessed their own tablet and $1 \%$ of them had their own smartphone. ${ }^{11}$ One 2017 publication found that more than half $(56 \%)$ of 489 American kids aged two to six-years had at least one media device in their bedrooms. ${ }^{12}$

Apart from increased media accessibility, environmental factors such as home media rules, parental media usage and parents' mediation strategies for controlling child screen time are likely to be determinants of child screen time. ${ }^{13,14,15}$ Home media rules consist not only of screen time restriction, but also decisions regarding the media content, and where and when media usage is allowed for children at home. For example, such rules may not allow usage of screen-based media during mealtimes or before bed or may limit the presence of screen-based media in the child's bedroom. ${ }^{16}$ A Japanese study among school children determined that homes that do not set media rules show higher involvement of children with screen-based media (OR 2.64, 95\% CI: $1.84-3.78) .{ }^{17}$

In another study of nearly three thousand American parents of children aged between three to ten-years, children of parents who watched more than two hours of television per day were 1.5 to 8 times more likely to exceed two hours of television viewing time per day. ${ }^{18}$ Parents with internet usage of more than two hours per day were found to be associated with prolonged screen time (OR 2.92, 95\% CI: 2.00 - 4.26) among children six to 13 years of age. ${ }^{19}$ In contrast, increased parental self-efficacy is found to be an effective factor in limiting child screen time and ensuring screen time recommendations are adhered to. Reduced parental self-efficacy was found to increase child screen time (weekdays $=\beta-0.15$, $\mathrm{p}=0.004$; weekends $=\beta-0.16, \mathrm{p}=0.004)$ in a study conducted among pre-schoolers in
Brazil. ${ }^{20}$ These studies show the importance of parental role in managing children's screen time.

Parental mediation strategies are vital for mitigating the effects of screen-based media on young children. ${ }^{21,22,23}$ Some of the strategies that can aid parents in managing their young children's screen time include setting limit in relation to daily events, such as not allowing television viewing before bedtime, offering alternatives to screen viewing, being consistent in screen time scheduling, negotiating with children regarding screen viewing time and encouraging child self-regulation. ${ }^{24}$

Excessive screen time among young children is associated with high chances of displacing parent-child interaction, which is fundamental to a thriving child's process of learning and development. ${ }^{25}$ Numerous publications have investigated the potential health impacts, especially in terms of child development, caused by screen-based media usage. Based on systematic search and reference tracking, some relevant studies are highlighted here. In a prospective cohort study that assessed the media usage of children at six months old and then reassessed at 14 months old, lower cognitive and language development were displayed among children with early exposure to electronic media, even after adjusting for confounders. Toddlers with 60 minutes of screen-based media exposure had lower developmental scores in both domains compared to their peers who had no exposure. ${ }^{26}$ A significant association between screen time and behavioural difficulties, including conduct and emotional problems, was observed in a study carried out with over 500 pre-schoolers between the ages of two and six years. The odds of children who use a mobile phone developing characteristics of hyperactivity or inattentiveness were three times greater than those for children who did not use mobile phones. $^{27}$

Young children with frequent television exposure showed developmental delay compared to those who were not exposed to television. Various degrees of likelihood of delay were recorded for three different developmental domains: cognitive development (OR: 3.9, 95\% CI: 1.4 - 5.9), language development (OR: 3.3, 95\% CI: 1.5 - 7.3) and motor skills development (OR: 3.7, 95\% CI: $1.5-9.3){ }^{28}$ In a prospective cohort study of more than 16,000 children between ages of two and nine 
years, every additional hour of screen time showed an increase of 1.2- to 2-fold in the probability of emotional problems and poorer family functioning. ${ }^{29}$ The impact of screen time on young children's social skills and emotional well-being has been a worrying issue in the minds of parents and is undeniably a public health concern, giving rise to much research in the field. ${ }^{30}$

A higher amount of screen time among children is also associated with increased risk of being overweight or obese. ${ }^{31,32}$ In a systematic review of sedentary behaviour and health indicators among school children and youths, $68 \%$ of longitudinal studies showed that greater amounts of television viewing at baseline were associated with steeper increases in body mass index (BMI), body weight and fat mass over time. ${ }^{33}$ In a study of Malaysian children aged seven to 12 years, children who had more screen time were found to be more likely to have a higher BMI-for age Z-score and waist circumference. ${ }^{34}$

As research regarding children's usage of digital technology moves forward, an important challenge is to understand where to draw the line between healthy and harmful use, which is likely to require an individual approach where each child and their overall life context is considered separately. Some recommendations from renowned international bodies or organisations are compiled below.

\section{(i) World Health Organization}

The "Guidelines on Physical Activity, Sedentary Behaviour and Sleep for Children under Five Years of Age" by World Health Organization (WHO) state that children within the first two years of life should not have any screenbased media exposure at all. For children aged two to four, screen time should not exceed more than an hour. ${ }^{35}$ This WHO guidelines are consistent with recommendations both the Commission on Ending Childhood Obesity ${ }^{36}$ and the Global Action Plan on Physical Activity $2018-2030 .^{37}$

\section{(ii) American Academy of Pediatrics}

As a general recommendation, the American Academy of Pediatrics (AAP) 2016 policy calls for limitation of screen time to one hour per day for children aged two to five years old. Further, 'highquality programming' that is viewed together with parents is encouraged. This policy was issued six years after the AAP's initial policy statement in 2010 that set a maximum of two hours screen time for children aged two to five. Children below the age of two are not encouraged to be exposed to any screen time at all. The AAP policy also recommends that parents not use screen-based media as the only tool to calm children and not be pressured for early screen-based media usage among children. For children allowed to use screen-based media, parents are to monitor the content of media with which the child is engaged. Bedrooms, mealtimes and playtimes are encouraged to be kept screen-free for children and parents, and screen-based media usage is to be prohibited an hour before bedtime. $^{38}$

(iii) National Association for the Education of Young Children

The National Association for the Education of Young Children (NAEYC), in its 2012 position statement 'Technology and Interactive Media as Tools in Early Childhood Programs Serving Children from Birth through Age 8', declared that technology and interactive media are tools that can promote effective learning and development, only when they are used within the framework of developmentally appropriate practices. A child's ability according to their developmental stage provides an idea of the activities, routines, interactions and curriculum that should be effective for each child. Each child is considered both as an individual and within the context of that child's specific family, community, culture, linguistic norms, social group and past experience. To be able to use technology and interactive media in ways that support children's learning and development, early childhood educators require information and resources concerning the nature of these tools and the implications of their use with children.

Some principles pointed out by the NAEYC include usage of media that gives careful attention to the quality of the media content, the child's experience, and opportunities for co-engagement. Interactions with technology and media are encouraged to be playful and support 
creativity, exploration, pretend play, active play and outdoor activities. Passive use of television, videos, DVDs and other non-interactive technologies and media in early childhood programs for children younger than two is prohibited, whilst passive and non-interactive uses with children aged two to five are discouraged. ${ }^{39}$

\section{Recommendations}

The Malaysian National Health and Morbidity Survey 2016 reported that $52.2 \%$ of children nationwide experience excessive screen time exposure, defined as any electronic media usage among children below the age of two and screen time of more than two hours among children aged 24 to 59 months. ${ }^{40}$ This warrants suitable recommendations for safe media usage among young children.

(i) Incorporate Safe Media Habits into Developmental Assessment

To spark awareness among parents regarding the potential health impacts of screen-based media usage among young children and for the purpose of developmental surveillance, child media habits could be incorporated as part of the toddler developmental assessment in health clinics. Queries concerning child's access to screen-based media, type of media used, media content engaged with and screen time could be integrated with the current developmental assessment system in Malaysia. Primary care physicians and nurses could take the opportunity to advise parents on screenbased media usage. Some general advice could include the following.

- Parents should be informed that screen-based media usage is not recommended for children below two years of age and for children aged two to five, screen time should not exceed an hour per day.

- Parents may reduce the risks associated with screen time by being present and engaged when screens are in use by children to promote active parent-child interaction.

- Parents should conduct selfassessment of their child's screen habits and develop their own usage plan.

- $\quad$ Parents and adult family members should model healthy screen use by choosing healthy alternatives to develop children's social engagement skills.

- Parents should be made to understand the importance of active parent-child interaction and that age-appropriate stimulation activities for toddlers should not be displaced by screen time.

(ii) Development of a Guideline on Safe Screen-based Media Usage for Young Children

A guideline especially focusing on children below the age of five and tailored to the Malaysian context ought to be developed based on current research, theory and practice. Usage of screenbased media for children below the age of two should be avoided altogether, at home and at early childcare centres or pre-schools. For older children, some of the guiding principles that can be included as a foundation of recommendation or policy development are as follows:

\section{Guiding Principle I: Screen Time Restriction}

The importance of having a safe media environment with parents as gatekeepers for children is supported by many studies. ${ }^{21,22,41}$ Thus, parental rules and enforcement strategies for the purpose of screen time restriction among children should be implemented. These strategies could include having a specific schedule for screen time per day that does not exceed the recommended time and no usage of screen-based media without permission from parents. ${ }^{42}$ For children between the ages of two and five sent to early childcare centres or pre-schools, screen time should be restricted on a daily or weekly basis, also considering any screen time that the child may have at home, for a sum of not more than an hour per day in average. ${ }^{35,38}$

\section{Guiding Principle II: Monitoring of Media Content}

The content of media children is engaged with should help them learn, imagine, express, or explore and not merely be a one-way communication tool. Children should be given the opportunity to learn and ask questions based on the media content shared. The content should 
not have age-inappropriate elements of violence or sexual content and should take into account religious and cultural sensitivity. Media content is encouraged to be viewed together with caregivers or educators who engage in a conversation with children while the media is played, rather than being viewed by children in isolation. ${ }^{38}$

Guiding Principle III: Developmentally Appropriate Technology Use for Learning

Usage of technology in home and preschools should be appropriately matched with a child's needs, abilities, interests and developmental stage, and should not displace time for interactive play or physical activities. ${ }^{39}$

Guiding Principle IV: Developing a Family Media Plan

Personalised screen-based media use for each family should be tailored according to the characteristics of the family, such as size, number and age of children, lifestyle and cultural values. Home media rules regarding screen-free time, screen-based media privacy and safety, and areas of the house and times of the day where media use is not allowed should be made clear by caregivers. For example, implementing rules of no screen time during meals and an hour before bedtime as recommended by the AAP. A structured schedule for screen time gives space for young children to engage themselves with other things such as interactive play, interaction with caregivers and physical activities. ${ }^{38}$

\section{(iii) Inter-agency Collaboration}

- Collaboration between the Ministry of Health and the Department of Social Welfare (Jabatan Kebajikan Masyarakat) under the Ministry of Women, Family and Community Development could pave the way in promoting healthy screen habits through parenting programmes and by conducting assessment of existing screen time policies in early childcare centres (pusat asuhan) and nurseries (taska) nationwide. Parental support groups can be formed to aid in sharing innovative and developmentally stimulating activities for the home that do not rely on screen-based media usage.

- Collaboration between the Ministry of Health and the Ministry of Education could result in integrating health promotion programmes and intervention strategies regarding screen-based media usage among children into the existing health and developmental assessment of School Health teams for preschoolers and children in lower primary school.

\section{Conclusion}

Early childhood is a period where a child's habits are cultivated. Facilitating children to develop their full potential in their early years gives high rates of return in later phases of life. Thus, the cost of failing to battle potential threats during this critical period should be taken seriously. ${ }^{43}$ Advocating quality care for young children in a conducive learning environment at homes and early childcare centres with mindful usage of screen-based media is vital to ensure that children of the younger generation achieve their optimal level of development. Providing parental care with protection from threats of technology and interactions that are responsive and emotionally supportive for toddlers is certainly an uphill task and is not a one-size-fits-all approach. Nevertheless, it is vital that parents, professionals and policy makers make the effort to create a developmentally stimulating environment in which children can grow.

\section{Conflict of interest}

The author declares no potential conflicts of interest with respect to the writing, authorship, and/or publication of this article.

\section{Ethical approval}

Not applicable

\section{Funding}

The author received no funding for this work 


\section{References}

1. Choo YY, Yeleswarapu SP, How CH, Agarwal P. Developmental assessment: Pactice tips for primary care physicians. Singapore Medical Journal. 2019; 60(2): 57-62. Available from http://www.smj.org.sg/sites/default/files/SMJ60-57.pdf DOI: 10.11622/smedj.2019016

2. Maggi S, Irwin LJ, Siddiqi A, Hertzman C. The social determinants of early child development: an overview. J Paediatr Child Health. 2010 Nov;46(11):627-35. DOI: 10.1111/j.14401754.2010.01817.x

3. Irwin LG, Siddiqi A, Hertzman C. Early child development: A powerful equalizer. World Health Organization's Commission on the Social Determinants of Health; 2007. Available from https:/www.who.int/social_determinants/ resources/ecd_kn_report_07_2007.pdf

4. Young ME. From early child development to human development. The World Bank. Washington D.C; 2002. Available from http://documents.worldbank.org/curated/ en/247161468336079362/pdf/239490PUB0Re pl0top0150500same0info0.pdf

5. Sigman A. Screen Dependency Disorders: a new challenge for child neurology. JICNA [Internet]. 2017Apr.19;1(1). Available from: https://jicna.org/index.php/journal/article/view/ jicna-2017-119

6. National Research Council (US); Institute of Medicine (US). Children's Health, The Nation's Wealth: Assessing and Improving Child Health. Washington (DC): National Academies Press (US); 2004. PMID: 22536616

7. Black MM, Walker SP, Fernald LCH, Andersen CT, DiGirolamo AM, Lu C, et al. Lancet Early Childhood Development Series Steering Committee. Early childhood development coming of age: science through the life course. Lancet. 2017 Jan 7;389(10064):77-90. DOI: $10.1016 /$ S0140-6736(16)31389-7.

8. Tomlinson M, Cooper P, Murray L. The motherinfant relationship and infant attachment in a South African peri-urban settlement. Child Dev. 2005 Sep-Oct;76(5):1044-54. DOI: 10.1111/j.1467-8624.2005.00896.x.
9. Vally Z, Murray L, Tomlinson M, Cooper PJ. The impact of dialogic book-sharing training on infant language and attention: a randomized controlled trial in a deprived South African community. J Child Psychol Psychiatry. 2015 Aug;56(8):865-73. DOI: 10.1111/jcpp.12352. Epub 2014 Nov 17.

10. Christensen MA, Bettencourt L, Kaye L, Moturu ST, Nguyen KT, Olgin JE, et al. Direct Measurements of Smartphone Screen-Time: Relationships with Demographics and Sleep. PLoS One. 2016 Nov 9;11(11):e0165331. DOI: 10.1371/journal.pone.0165331.

11. Children and parents: Media use and attitudes report. United Kingdom; 2017. Available from https://www.ofcom.org.uk/_data/assets/ pdf_file/0020/108182/children-parents-mediause-attitudes-2017.pdf

12. Quick V, Martin-Biggers J, Povis GA, Hongu N, Worobey J, Byrd-Bredbenner C. A SocioEcological Examination of Weight-Related Characteristics of the Home Environment and Lifestyles of Households with Young Children. Nutrients. 2017 Jun 14;9(6):604. DOI: $10.3390 /$ nu9060604.

13. Coyne SM, Radesky J, Collier KM, Gentile DA, Linder JR, Nathanson AI, et al. Parenting and Digital Media. Pediatrics. 2017 Nov;140(Suppl 2):S112-S116. DOI: 10.1542/peds.2016$1758 \mathrm{~N}$.

14. Tang L, Darlington G, Ma DWL, Haines J, on behalf of the Guelph Family Health S. Mothers' and fathers' media parenting practices associated with young children's screen-time: a crosssectional study. BMC Obesity. 2018;5(1):37. DOI: 10.1186/s40608-018-0214-4

15. Schoeppe S, Vandelanotte C, Bere E, Lien N, Verloigne M, Kovács É, et al. The influence of parental modelling on children's physical activity and screen time: Does it differ by gender? Eur J Public Health. 2017 Feb 1;27(1):152-157. DOI: 10.1093/eurpub/ckw182.

16. Radesky J. Policy addresses how to help parents manage young children's media use. American Academy of Pediatrics; 2016. Available from https://www.aappublications.org/ news/2016/10/21/MediaYoung102116
17. Yamada M, Sekine M, Tatsuse T. Parental Internet Use and Lifestyle Factors as Correlates of Prolonged Screen Time of Children in Japan: Results From the Super Shokuiku School Project. J Epidemiol. 2018 Oct 5;28(10):407413. DOI: $10.2188 /$ jea.JE20170100.

18. Jago R, Stamatakis E, Gama A, Carvalhal IM, Nogueira H, Rosado V, et al. Parent and child screen-viewing time and home media environment. Am J Prev Med. 2012 Aug;43(2):150-8. DOI: 10.1016/j. amepre.2012.04.012.

19. Myruski S, Gulyayeva O, Birk S, Pérez-Edgar K, Buss KA, Dennis-Tiwary TA. Digital disruption? Maternal mobile device use is related to infant social-emotional functioning. Dev Sci. 2018 Jul;21(4):e12610. DOI: 10.1111/desc. 12610.

20. Goncalves WSF, Byrne R, Viana MT, Trost SG Parental influences on screen time and weight status among preschool children from Brazil: a cross-sectional study. Int J Behav Nutr Phys Act. 2019 Mar 12;16(1):27. DOI: 10.1186/s12966019-0788-3.

21. Barkin S, Ip E, Richardson I, Klinepeter S, Finch S, Krcmar M. Parental media mediation styles for children aged 2 to 11 years. Arch Pediatr Adolesc Med. 2006 Apr;160(4):395-401. DOI: 10.1001/archpedi.160.4.395.

22. Nikken P, Schols M. How and Why Parents Guide the Media Use of Young Children. J Child Fam Stud. 2015;24(11):3423-3435. DOI: 10.1007/s10826-015-0144-4.

23. Jago R, Wood L, Zahra J, Thompson JL, Sebire SJ. Parental control, nurturance, self-efficacy, and screen viewing among 5- to 6-year-old children: a cross-sectional mediation analysis to inform potential behavior change strategies. Child Obes. 2015 Apr;11(2):139-47. DOI: 10.1089/ chi.2014.0110.

24. Jago R, Zahra J, Edwards MJ, Kesten JM, Solomon-Moore E, Thompson JL, et al. Managing the screen-viewing behaviours of children aged 5-6 years: a qualitative analysis of parental strategies. BMJ Open. 2016;6(3):e010355. DOI: 10.1136/ bmjopen-2015-010355. 
25. Christakis DA, Lowry SJ, Goldberg G, Violette $\mathrm{H}$, Garrison MM. Assessment of a ParentChild Interaction Intervention for Language Development in Children. JAMA Netw Open. 2019 Jun 5;2(6):e195738. DOI: 10.1001/ jamanetworkopen.2019.5738.

26. Tomopoulos S, Dreyer BP, Berkule S, Fierman AH, Brockmeyer C, Mendelsohn AL. Infant media exposure and toddler development. Arch Pediatr Adolesc Med. 2010 Dec;164(12):110511. DOI: 10.1001/archpediatrics.2010.235.

27. Poulain T, Vogel M, Neef M, Abicht F, Hilbert A, Genuneit J, et al. Reciprocal Associations between Electronic Media Use and Behavioral Difficulties in Preschoolers. Int J Environ Res Public Health. 2018 Apr 21;15(4):814. DOI: 10.3390/ijerph15040814.

28. Lin LY, Cherng RJ, Chen YJ, Chen YJ, Yang HM. Effects of television exposure on developmental skills among young children. Infant Behav Dev. 2015 Feb;38:20-6. DOI: 10.1016/j.infbeh.2014.12.005.

29. Hinkley T, Verbestel V, Ahrens W, Lissner L, Molnar D, Moreno LA, et al. Early Childhood Electronic Media Use as a Predictor of Poorer Well-being: A Prospective Cohort Study. JAMA Pediatr. 2014;168(5):485-492. DOI:10.1001/ jamapediatrics.2014.94

30. Rosen B. How to utilize research about children and screen time. The Family Institute at Northwestern University; 2019. Available from https://www.family-institute.org/sites/default/ files/pdfs/csi-ben-rosen-research-children-screentime-dec-2018.pdf

31. Schwarzfischer P, Gruszfeld D, Socha P, Luque V, Closa-Monasterolo R, Rousseaux $\mathrm{D}$, et al. Effects of screen time and playing outside on anthropometric measures in preschool aged children. PLoS One. $2020 \mathrm{Mar}$ 2;15(3):e0229708. DOI: 10.1371/journal. pone. 0229708 .
32. Veldhuis L, Vogel I, Renders CM, van Rossem L, Oenema A, HiraSing RA, et al. Behavioral risk factors for overweight in early childhood; the 'Be active, eat right' study. Int J Behav Nutr Phys Act. 2012 Jun 15;9:74. DOI: 10.1186/14795868-9-74.

33. Tremblay MS, LeBlanc AG, Kho ME, Saunders TJ, Larouche R, Colley RC, et al. Systematic review of sedentary behaviour and health indicators in school-aged children and youth. Int J Behav Nutr Phys Act. 2011 Sep 21;8:98. DOI: 10.1186/1479-5868-8-98.

34. Lee ST, Wong JE, Shanita SN, Ismail MN, Deurenberg P, Poh BK. Daily physical activity and screen time, but not other sedentary activities, are associated with measures of obesity during childhood. Int J Environ Res Public Health. 2014 Dec 23;12(1):146-61. DOI: 10.3390/ijerph120100146.

35. World Health Organization. Guidelines on physical activity, sedentary behaviour and sleep for children under 5 years of age. Geneva: WHO; 2019. Available from https://www.who. int/publications/i/item/guidelines-on-physicalactivity-sedentary-behaviour-and-sleep-forchildren-under-5-years-of-age

36. World Health Organization. Report of the Commission on Ending Childhood Obesity. Implementation plan: executive summary. Geneva: WHO; 2017. (WHO/NMH/PND/ ECHO/17.1). Licence: CC BY-NC-SA 3.0 IGO. Available from https://apps.who.int/iris/ bitstream/handle/10665/259349/WHO-NMHPND-ECHO-17.1-eng.pdf?sequence $=1$

37. World Health Organization. Global action plan on physical activity 2018-2030: More active people for a healthier world. Geneva: WHO; 2018. Licence: CC BY-NC-SA 3.0 IGO. Available at https://apps.who.int/iris/bitstream/ handle/10665/272722/9789241514187-eng.pdf
38. Council on Communications and Media Media and Young Minds. Pediatrics. 2016 Nov;138(5):e20162591. DOI: 10.1542/ peds.2016-2591.

39. National Association for the Education of Young Children and the Fred Rogers Center for Early Learning and Children's Media at Saint Vincent College. Technology and interactive media as tools in early childhood programs serving children from birth through age 8: Washington DC; 2012. Available from https://www.naeyc. org/sites/default/files/globally-shared/downloads/ PDFs/resources/topics/PS_technology_WEB.pdf

40. Ministry of Health. National health and morbidity survey, volume II: Maternal and child health findings. Institute for Public Health, Ministry of Health, Malaysia; 2016. Available from http:// iku.moh.gov.my/images/IKU/Document/ REPORT/2016/NHMS2016ReportVolumeIIMaternalChildHealthFindingsv2.pdf

41. Warren R. In Words and Deeds: Parental Involvement and Mediation of Children's Television Viewing. Journal of Family Communication. 2001;1(4):211-31. DOI: 10.1207/S15327698JFC0104_01

42. Ramirez ER, Norman GJ, Rosenberg DE, Kerr J, Saelens BE, Durant N, Sallis JF. Adolescent screen time and rules to limit screen time in the home. J Adolesc Health. 2011 Apr;48(4):37985. DOI: 10.1016/j.jadohealth.2010.07.013.

43. Richter LM, Daelmans B, Lombardi J, Heymann J, Boo FL, Behrman JR, et al; Paper 3 Working Group and the Lancet Early Childhood Development Series Steering Committee. Investing in the foundation of sustainable development: pathways to scale up for early childhood development. Lancet. 2017 Jan 7;389(10064):103-118. DOI: 10.1016/S01406736(16)31698-1. 